\title{
DETERMINAN KEGAGALAN ASI EKSKLUSIF PADA KOMUNITAS MADURA
}

\section{Determinants of Exclusive Breast Failure in Madura Communities}

\author{
10tik Widyastutik, ${ }^{2}$ Elly Trisnawati \\ ${ }^{12}$ Fakultas Ilmu Kesehatan, Universitas Muhammadiyah Pontianak, Indonesia \\ E-mail :otik@unmuhpnk.ac.id
}

\begin{abstract}
Exclusive breastfeeding is the first intake that is very important for infants aged 0-6 months. Exclusive breastfeeding achievement in the Madurese community in the working area of the outpatient Puskesmas Purun Kecil is 29\%. This is due to several things including the habit of giving honey to babies, therefore in giving ASI exclusively is interrupted. This study aims to analyze the relationship between the habit of giving honey to infants aged 0-6, the support of biological mothers from the baby's mother, the support of mother-in-law from the mother's baby, the support of health officers, the working status of a mother, the knowledge of lactation management, the effort to use the independent exclusive breastfeeding, and the exclusive breastfeeding failure. This study uses a cross sectional design. The study sample was 162. The statistical test used was the Chi-square test $\left(X^{2}\right)$. The results showed that the determinants of exclusive breastfeeding failure in infants in Peniraman Village and Nusapati Village were the support of biological mothers from the baby's mother, mother-in-law's support of the baby's mother, health worker support, lactation management knowledge, efforts to use independent ASI dairy equipment.
\end{abstract}

Keyword: Madura, Exclusive Breastfeeding Failure, Giving Honey, Mother/Mother in Law's Support, Lactation Management

\begin{abstract}
ASI eksklusif merupakan asupan pertama yang sangat penting bagi bayi usia 0 - 6 bulan.Capaian ASI eksklusif pada komunitas Madura di wilayah kerja Puskesmas Rawat Jalan Purun Kecil adalah 29\%.Hal ini dikarenakan beberapa hal diantaranya adalah kebiasaan memberikan madu kepada bayi, kurangnya dukungan ibu kandung dan ibu mertua dari ibu bayi terhadap pemberian ASI eksklusif sehingga keberhasilan dalam memberikan ASI secara eksklusif terganggu. Penelitian ini bertujuan untuk menganalisis hubungan kebiasaan pemberian madu kepada bayi usia 0-6, dukungan ibu kandung dari ibu bayi, dukungan ibu mertua dari ibu bayi , dukungan petugas kesehatan, status bekerja seorang ibu, pengetahuan manajemen laktasi, upaya penggunaan alat perah ASI mandiri pada kegagalan ASI Eksklusif. Penelitian ini menggunakan desain cross sectional. Sampel penelitian berjumlah 162.Uji statistik yang digunakan adalah uji Chi-square ( $\left.\mathrm{X}^{2}\right)$.

Hasil penelitian menunjukkan bahwa faktor penentu kegagalan ASI eksklusif pada bayi di Desa Peniraman dan Desa Nusapati adalah dukungan positif yang diberikan oleh ibu kandung dari ibu bayi, ibu mertua dari ibu bayi, petugas kesehatan, pengetahuan manajemen laktasi, dan upaya penggunaan alat perah ASI mandiri.

Kata kunci : Madura, Kegagalan ASI eksklusif, Pemberian Madu, Dukungan Ibu/ ibu Mertua, Manajemen Laktasi

12 Otik Widyastutik, Elly Trisnawati adalah Fakultas Ilmu Kesehatan, Universitas Muhammadiyah Pontianak, Indonesia
\end{abstract}




\section{PENDAHULUAN}

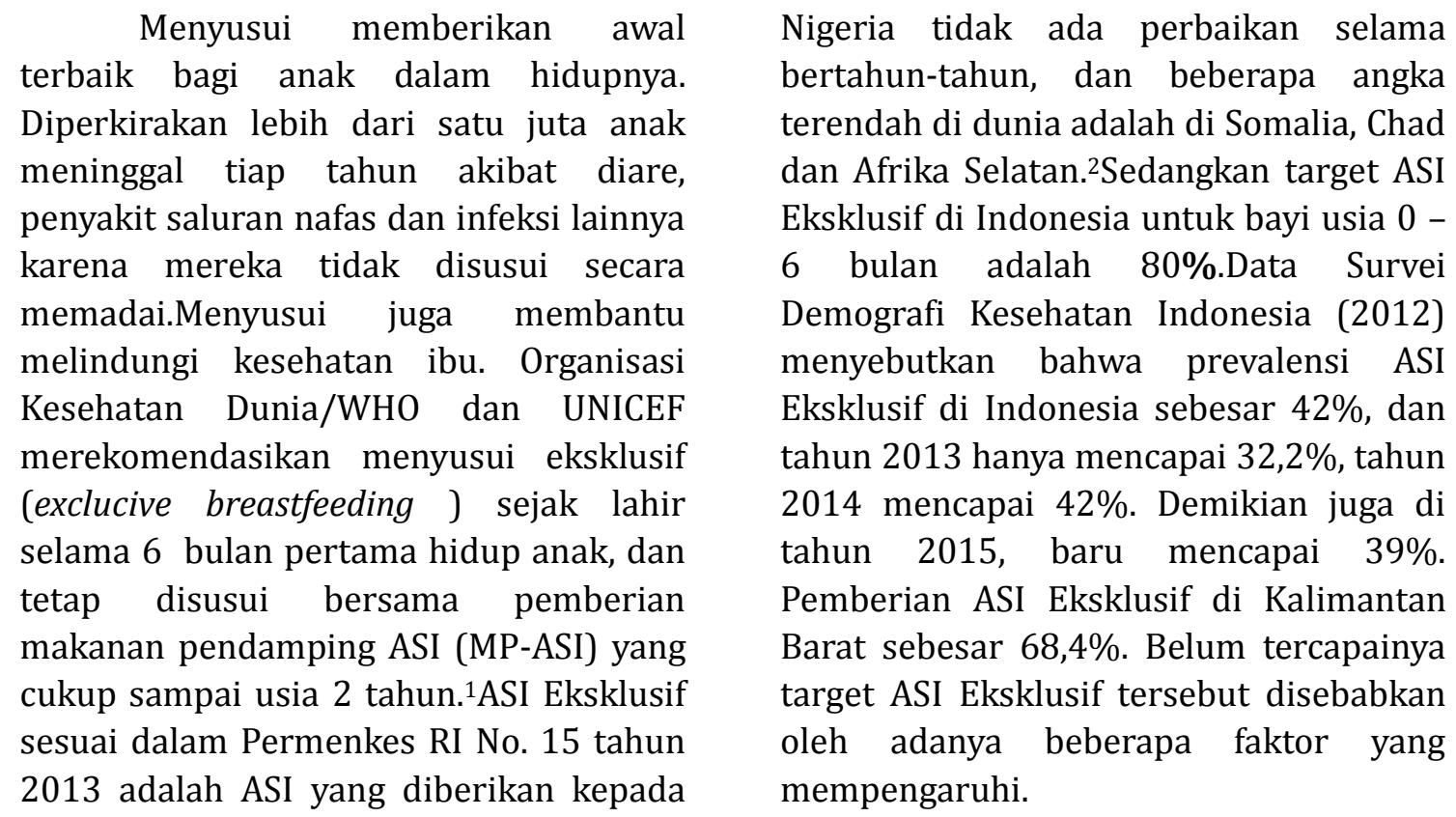
bayi sejak dilahirkan selama 6 (enam) bulan tanpa menambahkan dan atau mengganti dengan makanan atau minuman lain.

Kamboja berhasil meningkatkan tingkat pemberian ASI eksklusif untuk bayi di bawah 6 bulan secara drastis dari $11,7 \%$ pada tahun 2000 menjadi $74 \%$ pada tahun 2010. Togo dan Zambia juga meningkat dari 10 dan $20 \%$ pada akhir tahun 1990 menjadi lebih dari $60 \%$ pada tahun 2000. Pada sisi lainnya, tingkat pemberian ASI eksklusif di Tunisia turun drastis dari 46,5\% di tahun 2000 menjadi hanya $6,2 \%$ pada akhir dekade ini.
Diantaranya adalah kebiasaan memberikan madu pada bayi usia 0-6 bulan yang sudah menjadi kebudayaan turun-temurun yang dilakukan oleh ibu yang tinggal di wilayah desa Peniraman dan Desa Nusapati, dimana mayoritas dihuni oleh etnis Madura, kemudian dukungan keluarga (ibu kandung dan ibu mertua), dukungan tenaga kesehatan, pengetahuan ibu tentang manajemen laktasi, status pekerjaan, dan upaya penggunaan alat perah ASI secara mandiri. Beberapa determinan diatas dapat dibuktikan pada gambar 1 dibawah ini :
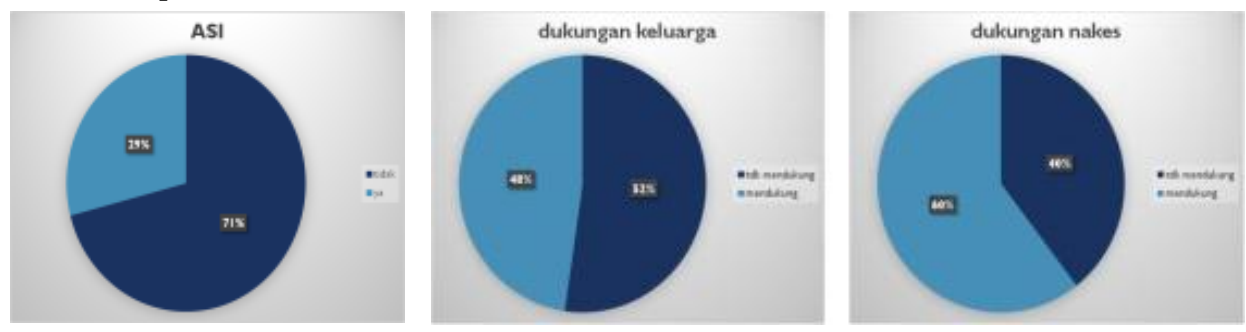

Gambar 1. Hasil Survei PKM 2017 Wilayah Kerja Puskesmas Rawat Jalan Purun Kecil tentang Capaian ASI Eksklusif, Dukungan Keluarga terhadap Praktik ASI Ekslusif, dan Dukungan Tenaga Kesehatan terhadap Praktik ASI Eksklusif Sumber : Hasil Survey PKM April 2017 
Banyak faktor yang dapat memicu seorang ibu gagal atau tidak dalam pemberian ASI eksklusif dalam suatu komunitas masyarakat dengan karakteristik tertentu. Secara kodrati seorang ibu tidak akan rela membiarkan bayinya menerima asupan selain ASI di masa awal kehidupannya (0 - 6 bulan). Akan tetapi dikarenakan kebiasaan yang dapat mengakibatkan kegagalan ASI eksklusif akhirnya menjadi budaya di masyarakat serta dukungan dari keluarga terutama ibu kandung dan ibu mertua, merupakan hal yang bisa menjadi faktor yang kuat terjadinya kegagalan pemberian ASI eksklusif. Hal tersebut dapat dilihat dari data survey PKM bulan April 2017 di wilayah kerja Puskesmas Rawat Jalan Purun Kecil yang menunjukkan bahwa jenis makanan yang diberikan ke bayi usia $<6$ bulan terbanyak adalah madu (36\%), diikuti oleh susu formula (34\%), bubur buatan sendiri (9\%), bubur buatan pabrik (6\%), air putih (6\%), makanan lainnya (4\%), air kelapa (2\%) dan nasi (1\%).

Hasil penelitian Rokhanawati dan Hidayati (2013) ${ }^{3}$ menunjukkan adanya hubungan antara sosial budaya dengan keberhasilan pemberian ASI eksklusif, yaitu berupa kebiasaan dan kepercayaan seseorang dalam pemberian ASI eksklusif misalnya mitos larangan makan makanan yang berbau amis (ikan,telur,ayam) dan kepercayaan bahwa kolostrum adalah cairan kotor yang harus dibuang. Dari hasil penelitian tersebut Rokhanawati dan Hidayati menyarankan agar orang tua lebih meningkatkan pemberian ASI eksklusif kepada bayinya.

Dukungan dari keluarga juga dapat menjadi determinan kegagalan pemberian ASI eksklusif. Siwi dan Rusminingsih (2014) ${ }^{4}$ menegaskan bahwa terdapat hubungan antara dukungan mertua dengan perilaku ASI eksklusif, penelitian dilakukan di Puskesmas Sewon 1 Yogyakarta, sebesar $p=0,040(p>0,05)$.
Hasil tersebut mendukung dari hasil survey lapangan di wilayah kerja Puskesmas Rawat Jalan Purun Kecil yang menunjukkan bahwa alasan terbanyak kedua terhadap kegagalan praktik ASI eksklusif setelah persepsi ASI tidak cukup (31\%), adalah karena dari pihak keluarga yang menganjurkan untuk tidak memberikan ASI eksklusif (20\%).

Beberapa penelitian juga membuktikan bahwa status pekerjaan ibu memiliki efek negatif terhadap durasi pemberian ASI. Hal ini menyebabkan ibu bekerja memiliki kesulitan untuk tetap memberikan ASI selama ibu bekerja. ${ }^{3}$ Cakupan ASI Eksklusif akan semakin rendah dikarenakan jumlah pekerja wanita semakin hari semakin bertambah, dengan jumlah peningkatan utama pada wanita usia produktif. Ibu yang bekerja harus meninggalkan bayinya untuk jangka waktu tertentu sehingga keberhasilan dalam memberikan ASI secara eksklusif terganggu.

Pengetahuan manajemen laktasi juga menjadi poin penting yang mempengaruhi ibu bekerja dalam memberikan ASI Eksklusif. Penelitian Slusser et al (2004)menunjukkan bahwa ibu yang bekerja selama 8 jam membutuhkan waktu selama 2-3 kali selama 30 menit untuk memompa ASI. Hal tersebut menjadi bagian yang harus dipahami oleh setiap ibu bekerja yang sedang memberikan ASI Eksklusif kepada bayinya. Lamanya jam kerja dan jam isirahat juga menentukan lama pemberian ASI Eksklusif pada ibu bekerja. Penelitian Ryan (2006) ${ }^{5}$ menjelaskan bahwa ibu yang bekerja paruh waktu juga memiliki kemungkinan untuk memberikan ASI lebih lama daripada ibu yang bekerja full time. Memerah ASI di tempat kerja baik dengan menggunakan pompa maupun menggunakan tangan juga dapat membantu pelaksanaan ASI Eksklusif berjalan lebih maksimal. Kepemilikan dan 
penggunaan alat bantu pompa ASI secara mandiri jika tidak bisa melakukan pemerahan secara manual menjadi faktor pendorong pemberian ASI Eksklusif. Memerah ASI dengan tangan akan memberikan stimulasi taktil pada areola yang akan memberikan tekanan pada kantong ASI. Tentunya hal ini dapat berjalan jika didukung oleh fasilitas/ruang laktasi di tempat kerja. Faktor dari keluarga juga menjadi salah satu yang perlu diperhatikan selain dari faktor tempat kerja dan faktor individu.Dukungan keluarga baik dari suami maupun orangtua dan mertua menjadi bagian penting yang dapat mendorong keberhasilan pemberian ASI Eksklusif pada ibu bekerja. Terutama jika bayi ditinggal di rumah bersama keluarga, maka perlu dukungan besar dari keluarga yang memegang bayi selama ibunya bekerja dengan tetap memberikan ASI perah yang telah disimpan di lemari pendingin ASI. Keluarga yang memberikan dukungan sepenuhnya kepada ibu, berpeluang 5,101 kali kepada ibu untuk bisa menyusui secara eksklusif dibandingkan ibu yang tidak mendapat dukungan keluarga. ${ }^{6}$

Fokus penelitian ini adalah pada komunitas Madura di wilayah kerja Puskesmas Rawat Jalan Purun Kecil. Berdasarkan observasi awal di komunitas tersebut, ditemukan bahwa sebanyak 71\% ibu (dari 162 sampel ibu komunitas Madura yang mempunyai bayi usia $<6$ bulan), terpaksa harus mengalami kegagalan dalam pemberian ASI Eksklusif. Hasil dari penelitian ini diharapkan dapat menjadi pijakan pemerintah daerah setempat dalam menyusun sebuah kebijakan dan komitmen dalam hal penyediaan fasilitas kelas laktasi dan penyuluhan rutin tentang manajemen laktasi kepada ibu bayi dan keluarga (ibu kandung/ibu mertuanya), serta menerbitkan buku panduan "Praktik Pemberian ASI Eksklusif" untuk ibu bayi dan keluarga.

Berdasarkan PP No. 33 tahun 2012 dan Permenkes No. 15 tahun 2013, diharapkan inisiasi ini akan menjadi pilot project untuk penyelenggaraan ASI eksklusif di tempat kerja dan menjadi bentuk nyata keterlibatan institusi tempat ibu bekerja dalam rangka mendukung terciptanya generasi, sehat, cerdas dan berkemajuan. Tidak hanya itu saja, bahkan hingga terciptanya kewirausahaan jasa kurir ASI yang akan mengantarkan ASI perahan ibu dari tempat bekerja ke tempat dimana bayi ibu berada.

\section{METODE PENELITIAN}

Variabel bebas dalam penelitian ini meliputi kebiasaan pemberian madu, dukungan ibu kandung dari ibu bayi, dukungan ibu mertua dari ibu bayi, dukungan petugas kesehatan, status bekerja ibu, pengetahuan tentang manajemen laktasi, dan upaya penggunaan alat perah ASI mandiri. Variabel terikat dalam penelitian ini adalah kegagalan ASI eksklusif.

Penelitian ini dilakukan di wilayah kerja Puskesmas Rawat Jalan Purun Kecil, Desa Nusapati. Desain penelitian adalah cross sectional. Teknik pengambilan sampel meggunakan teknik total sampling. Semua responden dalam populasi diambil sebagai sampel dalam penelitian ini, yaitu sebanyak $162 \mathrm{ibu}$ yang memiliki bayi usia 6-12 bulan. Teknik analisis data dengan menggunakan uji statistic chi-square. 
HASIL DAN PEMBAHASAN

Karakteristik Responden

Tabel 2. Distribusi frekuensi status bekerja ibu

\begin{tabular}{lll}
\hline Variabel & F & \% \\
\hline Status Bekerja Ibu & & \\
Bekerja & 42 & 25,9 \\
Tidak Bekerja & 120 & 74,1 \\
\hline Total & $\mathbf{1 6 2}$ & $\mathbf{1 0 0}$ \\
\hline
\end{tabular}

Berdasarkan tabel diatas dapat sebagai ibu rumah tangga) yaitu diketahui bahwa sebagian besar sebanyak 120 orang $(74,1 \%)$. responden tidak bekerja (hanya

Kebiasaan Pemberian Madu

Tabel 3. Distribusi frekuensi kebiasaan pemberian madu

\begin{tabular}{lll}
\hline Variabel & F & \% \\
\hline Kebiasaan Pemberian Madu & & \\
Diberikan & 123 & 75,9 \\
Tidak Diberikan & 39 & 24,1 \\
\hline Total & $\mathbf{1 6 2}$ & $\mathbf{1 0 0}$ \\
\hline
\end{tabular}

Berdasarkan tabel diatas dapat responden memiliki kebiasaan diberikan diketahui bahwa sebagian besar madu yaitu sebanyak 123 orang $(75,9 \%)$.

Dukungan Ibu Kandung Dari Ibu Bayi

Tabel 4. Distribusi frekuensi dukungan ibu kandung dari ibu bayi

\begin{tabular}{lll}
\hline Variabel & F & \% \\
\hline Dukungan Ibu Kandung Dari Ibu Bayi & & \\
Kurang mendukung & 55 & 34 \\
Mendukung & 107 & 66 \\
\hline Total & $\mathbf{1 6 2}$ & $\mathbf{1 0 0}$ \\
\hline
\end{tabular}

Berdasarkan tabel diatas dapat kandung dalam pemberian ASI eksklusif diketahui bahwa sebagian besar yaitu sebanyak 107 orang (66\%). responden mendapat dukungan dari ibu

Dukungan Ibu Mertua Dari Ibu Bayi

Tabel 5. Distribusi frekuensi dukungan ibu mertua dari ibu bayi

\begin{tabular}{lll}
\hline Variabel & F & \% \\
\hline Dukungan Ibu Mertua Dari Ibu Bayi & & \\
Kurang mendukung & 91 & 56,2 \\
Mendukung & 71 & 43,8 \\
\hline Total & $\mathbf{1 6 2}$ & $\mathbf{1 0 0}$ \\
\hline
\end{tabular}


Berdasarkan tabel diatas dapat dari ibu mertua pemberian ASI eksklusif diketahui bahwa sebagian besar yaitu sebanyak 91 orang (56,2\%). responden kurang mendapat dukungan

Dukungan Petugas Kesehatan

Tabel 6. Distribusi frekuensi dukungan petugas kesehatan

\begin{tabular}{lll}
\hline Variabel & F & $\mathbf{\%}$ \\
\hline Dukungan Petugas Kesehatan & & \\
Kurang mendukung & 78 & 48,1 \\
Mendukung & 84 & 51,9 \\
\hline Total & $\mathbf{1 6 2}$ & $\mathbf{1 0 0}$ \\
\hline
\end{tabular}

Berdasarkan tabel diatas dapat tenaga kesehatan yaitu sebanyak 84 orang diketahui bahwa sebagian besar (51,9\%). responden mendapat dukungan dari

Pengetahuan Manajemen Laktasi

Tabel 7. Distribusi frekuensi pengetahuan manajemen laktasi

\begin{tabular}{lll}
\hline Variabel & F & \% \\
\hline Pengetahuan Manajemen Laktasi & & \\
Kurang & 38 & 23,5 \\
Baik & 124 & 76,5 \\
\hline Total & $\mathbf{1 6 2}$ & $\mathbf{1 0 0}$ \\
\hline
\end{tabular}

Berdasarkan tabel diatas dapat manajemen laktasi yang baik yaitu diketahui bahwa sebagian responden sebanyak 124 orang (76,5\%). mempunyai pengetahuan tentang

Upaya Penggunaan Alat Perah ASI Mandiri

Tabel 8. Distribusi frekuensi upaya penggunaan alat perah ASI mandiri

\begin{tabular}{lll}
\hline Variabel & F & \% \\
\hline Upaya Penggunaan Alat Perah ASI & & \\
Mandiri & & \\
Tidak menggunakan & 124 & 76,5 \\
Menggunakan & 38 & 23,5 \\
\hline Total & $\mathbf{1 6 2}$ & $\mathbf{1 0 0}$ \\
\hline
\end{tabular}

Berdasarkan tabel diatas dapat ASI mandiri yaitu sebanyak 124 orang diketahui bahwa sebagian besar (76,5\%). responden tidak menggunakan alat perah 
Hubungan Kebiasaan Pemberian Madu terhadap Kegagalan ASI Eksklusif

Tabel 9. Analisis Hubungan Kebiasaan (Praktik) Pemberian Madu terhadap Kegagalan ASI Eksklusif

\begin{tabular}{|c|c|c|c|c|c|c|c|c|}
\hline \multirow{3}{*}{ Variabel } & \multicolumn{5}{|c|}{ Kegagalan ASI Eksklusif } & \multirow[b]{2}{*}{ Total } & \multirow{3}{*}{ p-value } & \multirow{3}{*}{$\begin{array}{c}\text { PR } \\
\text { (CI 95\%) }\end{array}$} \\
\hline & \multicolumn{2}{|c|}{$\begin{array}{l}\text { Gagal ASI } \\
\text { Eksklusif }\end{array}$} & \multicolumn{3}{|c|}{$\begin{array}{c}\text { Berhasil ASI } \\
\text { Eksklusif }\end{array}$} & & & \\
\hline & $\mathbf{N}$ & $\%$ & $\mathbf{N}$ & $\%$ & $\mathbf{N}$ & $\%$ & & \\
\hline $\begin{array}{l}\text { Kebiasaan (Praktik) } \\
\text { Pemberian Madu }\end{array}$ & & & & & & & 0,000 & $\begin{array}{l}19,500 \\
(5,056-\end{array}$ \\
\hline Diberikan & 123 & 75,9 & $\mathbf{0}$ & $\mathbf{0}$ & 123 & 75,9 & & $75,212)$ \\
\hline Tidak diberikan & 2 & 1,2 & 37 & 22,8 & 39 & 24,1 & & \\
\hline
\end{tabular}

Tabel 3. Determinan Kegagalan Asi Eksklusif Pada Komunitas Madura

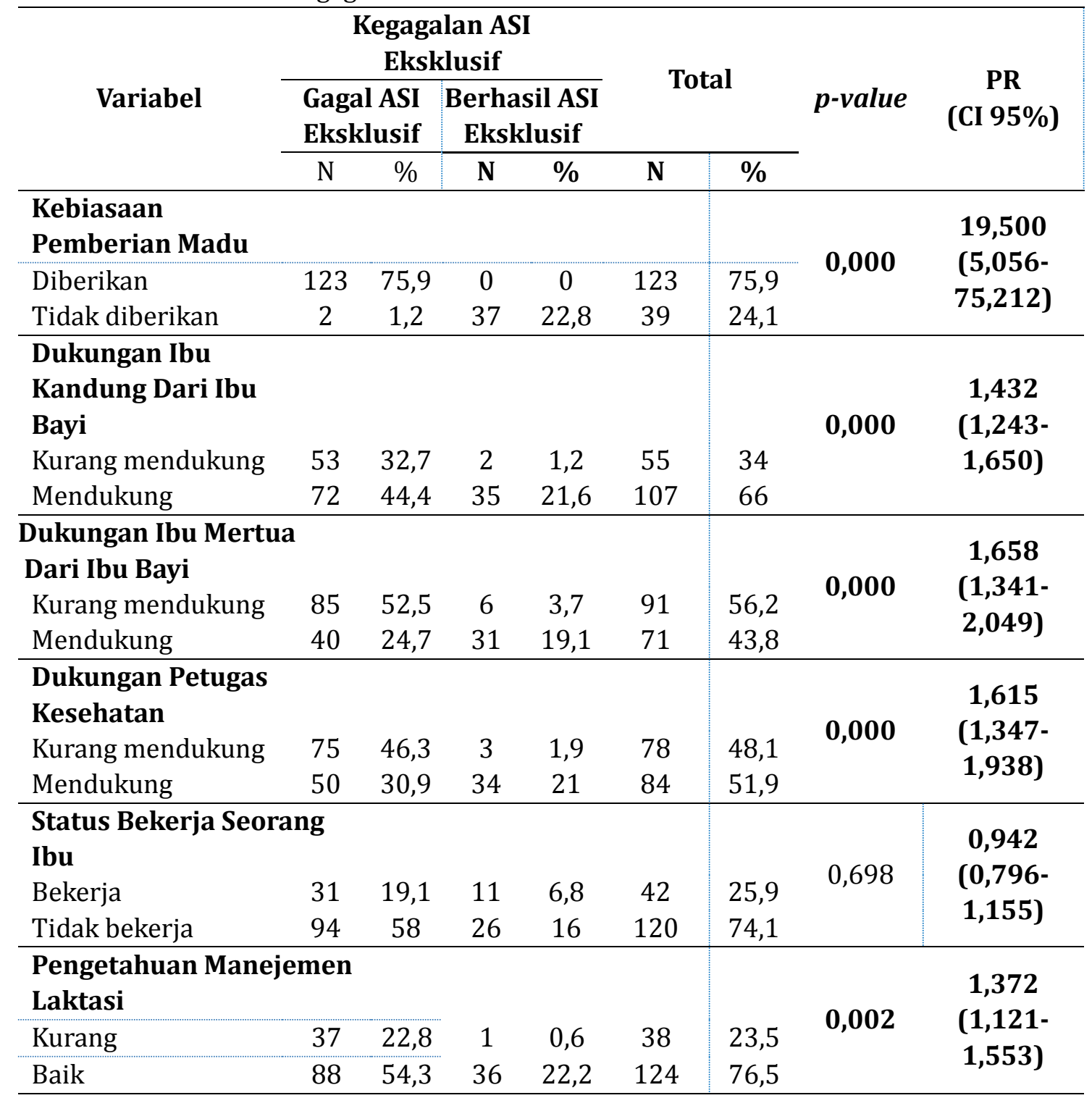




\begin{tabular}{|c|c|c|c|c|c|c|c|c|}
\hline \multirow{3}{*}{ Variabel } & \multicolumn{4}{|c|}{$\begin{array}{c}\text { Kegagalan ASI } \\
\text { Eksklusif }\end{array}$} & \multirow{2}{*}{\multicolumn{2}{|c|}{ Total }} & \multirow{3}{*}{ p-value } & \multirow{3}{*}{$\begin{array}{c}\text { PR } \\
\text { (CI 95\%) }\end{array}$} \\
\hline & \multicolumn{2}{|c|}{$\begin{array}{l}\text { Gagal ASI } \\
\text { Eksklusif }\end{array}$} & \multicolumn{2}{|c|}{$\begin{array}{l}\text { Berhasil ASI } \\
\text { Eksklusif }\end{array}$} & & & & \\
\hline & $\mathrm{N}$ & $\%$ & $\mathbf{N}$ & $\%$ & $\mathbf{N}$ & $\%$ & & \\
\hline $\begin{array}{l}\text { Penggunaan Alat } \\
\text { Perah ASI Mandiri }\end{array}$ & & & & & & & & 1,290 \\
\hline $\begin{array}{l}\text { Tidak } \\
\text { menggunakan }\end{array}$ & 101 & 62,3 & 23 & 14,2 & 124 & 76,5 & 0,033 & $\begin{array}{c}(0,997- \\
1,667)\end{array}$ \\
\hline Menggunakan & 24 & 14,8 & 14 & 8,6 & 38 & 23,5 & & \\
\hline
\end{tabular}

Sumber : Data Primer, 2018

Berdasarkan tabel di atas di
ketahui bahwa ada yangberhubungan dengan kegagalan ASI Eksklusif, yaitu kebiasaan pemberian madu kepada bayi usia 0-6 (p-value $0,000)$, dukungan ibu kandung dari ibu bayi ( $p$-value 0,000), dukungan ibu mertua dari ibu bayi ( $p$-value 0,000), dukungan petugas kesehatan ( $p$-value $0,000)$, pengetahuan manajemen laktasi ( $p$-value 0,002$)$, upaya penggunaan alat perah ASI mandiri ( $p$-value0,033).

Ibu yang mendapatkan dukungan dari ibu kandungnya tidak memberikan ASI eksklusif karena hanya mendapatkan dukungan informatif. Hal ini sejalan dengan hasil analisis pengetahuan ibu mengenai manajemen laktasi. Mayoritas ibu mendapat dukungan dari ibu kandung dan mempunyai pengetahuan yang baik mengenai manajemen laktasi namun tidak memberikan ASI eksklusif kepada bayinya karena ibu belum mengerti sepenuhnya tentang pentingnya ASI eksklusif bagi bayi. Pengalaman saat kecil dan pengalaman dari orang di sekitar ibu yang tidak memberikan ASI eksklusif kepada bayinya dianggap aman dan cenderung efektif untuk membantu ibu menenangkan bayi saat bayi menangis. Ibu percaya bahwa memberikan makanan lain selain ASI pada bayi usia $<6$ bulan tidak memberikan pengaruh yang buruk untuk bayinya walaupun jika mendapat ASI eksklusif akan lebih baik.
Mayoritas ibu tidak bekerja atau bekerja sebagai ibu rumah tangga tetapi tidak memberikan ASI eksklusif untuk bayinya karena pekerjaan rumah yang sangat banyak. Ibu berusaha untuk membuat bayinya tenang lebih lama dengan memberikan makanan lain selain ASI agar bayi bisa ditinggal lebih lama dan ibu dapat mengerjakan pekerjaan rumah dengan tenang.

\section{Hubungan kebiasaan pemberian madu dengan kegagalan ASI Eksklusif \\ Hasil penelitian hubungan} kebiasaan pemberian madu kepada bayi usia 0-6 pada kegagalan ASI Eksklusif menunjukkan bahwa proporsi responden yang diberikan madu lebih banyak mengalami kegagalan ASI Eksklusif yaitu sebesar 75,9\% dibandingkan dengan responden yang tidak diberikan madu yaitu sebesar $1,2 \%$. Hasil penelitian menunjukan bahwa kebiasaan pemberian madu kepada bayi usia 0-6 merupakan faktor penentu kegagalan ASI Eksklusif.

ASI Eksklusif adalah pemberian ASI saja pada bayi sampai usia 6 bulan tanpa tambahan cairan ataupun makanan lain. Dulu, rekomendasi WHO ASI Eksklusif hanya diberikan hingga usia bayi 4 bulan. Namun, kini WHO merekomendasikan ASI diberikan secara Eksklusif hingga usia bayi 6 bulan.Waktu yang direkomendasikan WHO untuk 
memberikan ASI eksklusif selama 6 bulan bukan tanpa alasan. Dalam kajian WHO, melakukan penelitian menunjukan bahwa ASI mengandung semua nutrisi yang diperlukan bayi. Sejalan dengan WHO, menteri kesehatan melalui kepmenkes RI No. 450/MENKES/IV/2004 pun akhirnya menetapkan perpanjangan pemberian ASI secara Eksklusif dari 4 bulan menjadi 6 bulan. Jadi jika bayi usia 0-6 bulan diberikan madu maka statusnya tidak lagi ASI Eksklusif.

Memberikan madu pada bayi sudah menjadi kebudayaan turuntemurun yang dilakukan oleh ibu-ibu yang tinggal di wilayah desa Peniraman dan desa Nusapati, karana dianggap bayi akan menjadi lebih sehat. Gambaran kebudayaan atau kebiasaan daerah setempat dapat mengakibatkan kegagalan ASI eksklusif. Informasi yang diperoleh dari hasil penelitian ini, yaitu sebagian besar responden mengaku memberikan madu. Alasan yang mendasari responden memberikan madu adalah karena adanya anjuran dari ibu atau mertua yang telah menanamkan kebiasan-kebiasaan tersebut sebagai bagian dari adat/budaya yang diwariskan.

Ibu seharusnya tidak boleh memberikan makanan atau minuman apapun termasuk madu kepada bayi baru lahir. Meskipun madu merupakan makanan yang banyak mengandung vitamin tetapi bukan bukan diperuntukkan bagi bayi usia 0-6 bualan, karena menurut Fikawati $(2015)^{7}$, hal tersebut dapat menjadi jalan masuknya kuman dan bakteri kedalam tubuh bayi dan menjadi salah satu factor penyebab kegagalan pemberian ASI eksklusif 20 .

Himbauan dari WHO yaitu melarang diberikan madu pada bayi dibawah usia 1 tahum. Disebabkan pada madu mengandung spora yang berbahaya dan mematikan bagi bayi yang disebut Clostridium botulinum. ${ }^{8}$
Menurut Reosli, 2001 bayi usia 0-6 bulan cukup diberi ASI saja, karna ASI merupakan makanan yang terbaik bagi bayi pada 6 bulan pertama kehidupan. Semua kebutuan nutrisi yaitu protein, karbohidrat, lemak, vitamin, dan mineral sudah tercukupi dari ASI. ${ }^{9}$

\section{Hubungan dukungan ibu kandung dari ibu bayi dengan kegagalan ASI Eksklusif}

Hasil penelitian dukungan ibu kandung dari ibu bayi pada kegagalan ASI Eksklusif menunjukkan bahwa proporsi ibu kandung dari ibu bayi yang mendukung lebih banyak mengalami kegagalan ASI Eksklusif yaitu sebesar $44,4 \%$ dibandingkan dengan responden yang tidak mendapat dukungan yaitu sebesar 32,7\%. Hasil penelitian menunjukan bahwa dukungan ibu kandung dari ibu bayi merupakan faktor penentu kegagalan ASI Eksklusif. Dukungan berupa informasi mengenai pentingnya ASI eksklusif dan pertolongan secara langsung sangat membantu ibu dari ibu bayi untuk dapat memberikan ASI eksklusif.

Hasil ini sejalan dengan penelitian dengan penelitian yang dilakukan oleh Angraresti (2016) ${ }^{10}$, dalam penelitiannya menunjukkan bahwa terdapat hubungan yang bermakna antara dukungan ibu kandung dengan kegagalan ASI Eksklusif $(\mathrm{p}=0,000)$. Penelitian lainnya yang dilakukan oleh Kurniawati (2014) ${ }^{11 j u g a}$ menemukan bahwa ada hubungan antara dukungan ibu kandung dengan kegagalan ASI Eksklusif ( $p=0,024)$.

Pemberian Air susu ibu (ASI) oleh ibu menyusui memerlukan dukungan dari orang terdekat termasuk orang tua atau ibu kandung, karna dianggap sebagai pihak yang paling mampu memberikan pengaruh kepada ibu untuk memaksimalkan pemberian ASI eksklusif. Dukungan atau support dari orang lain 
atau orang terdekat, sangatlah berperan dalam sukses tidaknya menyusui. Semakin besar dukungan yang didapatkan untuk terus menyusui maka akan semakin besar pula kemampuan untuk dapat bertahan terus untuk menyusui. ${ }^{12}$

Menurut penelitian Britton, 2007 dalam Nurlinawati, 2016 menemukan bahwa dukungan keluarga yang berasal dari suami dan anggota keluarga lainnya (ibu) meningkatkan durasi menyusui sampai enam bulan pertama postpartum dan memegang peranan penting dalam keberhasilan pemberian ASI eksklusif. ${ }^{13}$

\section{Hubungan dukungan ibu mertua dari ibu bayi dengan kegagalan ASI Eksklusif}

Hasil penelitian dukungan ibu mertua dari ibu bayi pada kegagalan ASI Eksklusif menunjukkan bahwa proporsiibu mertua dari ibu bayi yang kurang mendukung lebih banyak mengalami kegagalan ASI Eksklusif yaitu sebesar 52,5\% dibandingkan dengan responden yang mendapat dukungan yaitu sebesar 24,7\%. Hasil penelitianmenunjukan bahwa dukungan ibu mertua dari ibu bayi berupa informasi mengenai ASI eksklusif, dukungan moral dan cara yang baik dan benar dalam pemberian ASI merupakan faktor penentu kegagalan ASI Eksklusif.

Hasil ini sejalan dengan penelitian dengan penelitian yang dilakukan oleh Angraresti(2016), ${ }^{10}$ dalam penelitiannya menunjukkan bahwa terdapat hubungan yang bermakna antara dukungan ibu mertua dengan kegagalan ASI Eksklusif $(\mathrm{p}=0,000)$. Penelitian lainnya yang dilakukan oleh Siwi $(2014)^{2}$ juga menemukan bahwa ada hubungan antara dukungan ibu mertua dengan kegagalan ASI Eksklusif $(p=0,040)$.

Dukungan ibu mertua sangat diperlukan agar ibu dapat menyusui secara eksklusif, ibu mertua sebagai bagian dalam keluarga memegang peran sangat penting dalam upaya ini, karana dukungan tersebut menentukan kelancaran refleks pengetahuan ASI (let down reflex) yang sangat dipengaruhi oleh emosi dan perasaan ibu menyusui. ${ }^{14}$ Dukungan emosional dari ibu mertua dapat menjadikan ibu menjadi lebih tenang dan nyaman untuk senantiasa memberikan ASI Eksklusif kepada bayinya.

\section{Hubungan dukungan tenaga kesehatan dengan kegagalan ASI Eksklusif}

Hasil penelitian dukungan tenaga kesehatan pada kegagalan ASI Eksklusif menunjukkan bahwa proporsitenaga kesehatan yang kurang mendukung responden lebih banyak mengalami kegagalan ASI Eksklusif yaitu sebesar 46,3\% dibandingkan dengan responden yang mendapat dukungan yaitu sebesar $30,9 \%$. Hasil penelitian menunjukan bahwa dukungan tenaga kesehatan berupa konseling mengenai manajemen laktasi, pentingnya ASI eksklusif bagi bayi, dan kunjungan rumah yang dilakukan oleh petugas kesehatan merupakan faktor penentu kegagalan ASI Eksklusif.

Hasil ini sejalan dengan penelitian dengan penelitian yang dilakukan oleh Angraresti (2016),10 dalam penelitiannya menunjukkan bahwa terdapat hubungan yang bermakna antara dukungan tenaga kesehatan dengan kegagalan ASI Eksklusif $(\mathrm{p}=0,000)$. Penelitian lainnya yang dilakukan oleh Kurniawati (2014) ${ }^{11}$ juga menemukan bahwa ada hubungan antara dukungan tenaga kesehatan dengan kegagalan ASI Eksklusif ( $\mathrm{p}=0,009)$.

Salah satu keberhasilan ASI Eksklusif adalah mempersiapkan payudara sejak masa kehamilan, memilih tempat melahirkan yang sayang bayi seperti rumah sakit sayang bayi atau rumah bersalin sayang bayi dan memilih 
tenaga kesehatan yang mendukung pemberian ASI secara Eksklusif.15 Dukungan petugas kesehatan dalam hal ini terutama adalah bidan, dapat memberikan pengaruh besar terhadap ibu dalam menentukan keberhasilan pemberian ASI Eksklusif. Hal tersebut sesuai dengan pendapat Notoatmodjo (2010) bahwa pengetahuan dan sikap petugas kesehatan dalam memberikan penyuluhan atau dorongan tentang manfaat pemberian ASI sangat menentukan keberhasilan ibu menyusui. ${ }^{16}$

Dengan adanya peran dari petugas kesehatan terutama bidan dapat berupa bimbingan dan konsultasi tentang permasalahan menyusui pada bayi. Dan membantu meyakinkan ibu untuk dapat menyusui bayinya sendiri dan dukungan petugas kesehatan dapat berupa pemberian informasi tentang manfaat ASI eklusif dan dapat mempengaruhi perilaku ibu untuk memberikan ASI eksklusif.

\section{Hubungan status bekerja seorang ibu dengan kegagalan ASI Eksklusif ibu bekerja}

Hasil penelitian status bekerja seorang ibu pada kegagalan ASI Eksklusif menunjukkan bahwa proporsi responden yang status ibu tidak bekerja lebih banyak mengalami kegagalan ASI Eksklusif yaitu sebesar $58 \%$ dibandingkan dengan responden yang bekerja yaitu sebesar 19,1\%. Hasil penelitianmenunjukan bahwa status pekerjaan ibu dalam penelitian ini bukan merupakan faktor penentu kegagalan ASI Eksklusif.

Hasil ini sejalan dengan penelitian dengan penelitian yang dilakukan oleh Angraresti (2016), ${ }^{10}$ dalam penelitiannya menunjukkan bahwa tidak terdapat hubungan yang bermakna antara status pekerjaan ibu dengan kegagalan ASI Eksklusif $(p=0,133)$. Penelitian lainnya yang dilakukan oleh Wijayanti, dkk
(2017) ${ }^{17}$ juga menemukan bahwa tidak ada hubungan antara status pekerjaan ibu dengan kegagalan ASI Eksklusif ( $\mathrm{p}=$ $0,630)$.

Hasil penelitian ini juga sejalan dengan pendapat Roesli (2009) ${ }^{15}$ bahwa bekerja bukan alasan untuk menghentikan pemberian ASI Eksklusif. Pemberian ASI Eksklusif merupakan hal terbaik bagi bayi. Hal ini didukung oleh bukti secara ilmiah bahwa bayi yang diberi ASI Eksklusif akan lebih sehat dibandingkan dengan bayi yang tidak diberikan ASI. Bayi yang tidak diberikan ASI Eksklusif akan mengalami 3 kali lebih sering dirawat daripada bayi yang diberikan ASI Eksklusif. Hal ini berarti bayi yang diberikan ASI Eksklusif lebih jarang dibawa ke dokter sehingga ibu lebih jarang meninggalkan pekerjaan.

Pada ibu yang bekerja, menyusui bayi tidak perlu dihentikan.Ibu yang bekerja tetap harus memberikan ASI kepada bayinya.Jika memungkinkan bayi dapat diajak ke tempat ibu bekerja. Namun, hal ini akan sulit dilaksanakan apabila di tempat kerja atau di sekitar tempat kerja tidak tersedia sarana penitipan bayi atau pojok laktasi. Walaupun ibu bekerja dan tempat kerja jauh dari rumah, ibu harus tetap memberikan ASI kepada bayinya. ${ }^{15}$

\section{Hubungan \\ pengetahuan manajemen laktasi dengan kegagalan ASI Eksklusif}

Hasil penelitian pengetahuan manajemen laktasi pada kegagalan ASI Eksklusif menunjukkan bahwa proporsi responden yang pengetahuan manajemen laktasinya baik lebih banyak mengalami kegagalan ASI Eksklusif yaitu sebesar $54,3 \%$ dibandingkan dengan responden yang pengetahuan manajemen laktasinya kurang yaitu sebesar 22,8\%. Hasil penelitian menunjukan bahwa pengetahuan ibu-ibu tentang manajemen 
laktasi yaitu cara menyusui yang baik, perawatan payudara untuk melancarkan ASI, frekuensi dan durasi bayi menyusui, dan cara memerah ASI merupakan faktor penentu kegagalan ASI Eksklusif.

Hasil ini sejalan dengan penelitian dengan penelitian yang dilakukan oleh Angraresti (2016) ${ }^{10}$, dalam penelitiannya menunjukkan bahwa terdapat hubungan yang bermakna antara pengetahuan ibu dengan kegagalan ASI Eksklusif ( $\mathrm{p}=$ 0,000 ). Penelitian lainnya yang dilakukan oleh Kurniawati (2014) ${ }^{11}$ juga menemukan bahwa ada hubungan antara pengetahuan ibu dengan kegagalan ASI Eksklusif ( $p=0,008)$.

Pengetahuan berkaitan dengan informasi. Informasi yang didapat mempunyai nilai nyata dan akan berpengaruh pada keputusan yang akan diambil untuk waktu sekarang atau pada waktu yang akan mendatang. Sesuai dengan pendapat Notoatmodjo (2003) ${ }^{18}$ yang menyatakan bahwa perilaku seseorang akan terbentuk dalam pengetahuan. Sesuai dengan kerangka kerja PRECEDE dari Green yang menyatakan bahwa tingkat pengetahuan merupakan faktor predisposisi dalam perilaku positif, karena dengan pengetahuan seseorang akan mulai mengenal dan mencoba atau melakukan suatu tindakan. Penambahan pengetahuan tidak bisa dilakukan hanya dalam waktu singkat, tetapi harus terus menerus dan berkelanjutan juga memberikan informasi.

Pengetahuan merupakan faktor penting yang mempengaruhi sikap dan perilaku sesorang. Kurangnya pengetahuan dapat berpengaruh pada tindakan yang dilakukan karena pengetahuan merupakan salah satu faktor predisposisi untuk terjadinya perilaku. Oleh karena itu pengetahuan tentang manajemen laktasi merupakan hal yang penting dalam mempengaruhi tindakan ibu untuk memberikan ASI Eksklusif kepada bayinya.

\section{Hubungan upaya penggunaan alat perah ASI mandiri dengan kegagalan ASI Eksklusif \\ Hasil penelitian upaya} penggunaan alat perah ASI mandiri pada kegagalan ASI Eksklusif menunjukkan bahwa proporsi responden yang tidak menggunakan alat perah ASI mandiri lebih banyak mengalami kegagalan ASI Eksklusif yaitu sebesar 62,3\% dibandingkan dengan responden yang menggunakan yaitu sebesar $14,8 \%$. Hasil penelitian menunjukan bahwa upaya penggunaan alat perah ASI mandiri merupakan faktor penentu kegagalan ASI Eksklusif.

Hasil ini sejalan dengan penelitian dengan penelitian yang dilakukan oleh Anggreni (2018) ${ }^{10}$, dalam penelitiannya menunjukkan bahwa terdapat pengaruh penggunaan Pompa ASI (MPA) terhadap pemberiaan ASI ekslusif pada ibu pekerja (Sig $=0,000 \leq 0,05$ )

Penggunaan alat perah ASI mandiri atau metode pompa ASI (MPA) merupakan salah satu metode yang dapat menfasilitasi pemberian ASI pada bayi, untuk menyediakan kebutuhan ASI, metode MPA secara langsung akan mendukung program pemberian ASI secara ekslusif. MPA juga merupakan metode paling cepat dan efisien untuk meningkatkan produksi ASI, selain itu akan memberikan rasa nyaman pada ibu dan rasa percaya diri untuk terus menyusui juga semakin bertambah. Sehingga keinginan untuk menyusui secara ekslusif itu bertambah. Banyak maanfaat dari MPA yang akan diterima bayi, ASI mengandung berbagai vitamin dan nutrisi yang sangat dibutuhkan oleh bayi. ${ }^{19}$ 


\section{PENUTUP}

Berdasarkan hasil penelitian yang telah dilakukan kepada 162 ibu-ibu di Desa Peniraman dan Desa Nusapati, wilayah kerja Puskesmas Purun Kecil, menunjukkan rerata usia responden dalam penelitian ini adalah 28,9 tahun dengan usia termuda adalah 18 tahun dan usia tertua 42 tahun, sebagian besar responden adalah ibu rumah tangga (IRT) sebesar 74,1\%, Pemberian madu kepada bayi baru lahir, dukungan ibu kandung dari ibu bayi, dukungan ibu mertua dari ibu bayi, dukungan petugas kesehatan, status bekerja seorang ibu, pengetahuan manajemen laktasi, dan upaya penggunaan alat perah ASI mandiri merupakan faktor penentu kegagalan ASI eksklusif.

Saran atau rekombagi Puskesmas Sungai Purun Kecil, diharapkan dapat menyusun kebijakan terkait pelaksanaan edukasi tentang manajemen laktasi secara berkelanjutan, pembinaan secara berkelanjutan kepada bidan-bidan desa, penyuluhan tentang manajemen laktasi dan pentingnya ASI eksklusif,

\section{DAFTAR RUJUKAN}

[1] Depkes, RI. 2007. Pelatihan Konseling Menyusui.Jakarta : Dirjen Bina Kesehatan Masyarakat Direktorat Bina Gizi Masyarakat.

[2] World Health Organization (WHO). 2003. Global Strategy for Infant and Young Child Feeding. Geneva:WHO

[3] Hidayati, Hajaroh dan Rokhnawati, Dewi. 2013. Hubungan Sosial Budaya denganKeberhasilan Pemberian ASI Eksklusif pada Ibu Menyusui di Posyandu Wilayah Desa Srigading Sanden Bantul Yogyakarta. http://opac.unisayogya.ac.id/1267/ menggerakkan masyarakat untuk lebih peduli terhadap keberhasilan pemberian ASI eksklusif.

Bagi ibu bayi diharapakan ibu bayi dapat lebih meningkatkan pemahaman yang lebih mendalam mengenai pentingnya ASI eksklusif serta praktik manajemen laktasi.Selain itu ibu bayi harus lebih pro aktif dalam mencari informasi terkait ASI dan cara-cara pengeluaran ASI yang maksimal, salah satunya adalah dengan menerapkan upaya penggunaan alat perah ASI mandiri baik secara manual (tangan/alat non elektrik) maupun elektrik.

Bagi keluarga diharapkan dapat memberikan dukungan penuh kepada ibu bayi agar dapat memberikan ASInya secara eksklusif kepada bayi yang dilahirkan, memaksimalkan peran suami dan ibu maupun ibu mertua sebagai pendamping pengasuhan bayi untuk melaksanakan manajemen laktasi, dan menghentikan kebiasaan pemberian madu pada bayi yang baru dilahirkan

1/NASKAH\%20PUBLIKASI.pdf. Di unduh tanggal 7 Juni 2016

[4] Siwi, Tyas K \& Ruminingsih. 2015. Hubungan Dukungan Mertua Dengan ASI Eksklusif Di Puskesmas Sewon I Bantul Bulan Desember 2013- Juli 2014. http://opac.unisayogya.ac.id/view/ creators $/$ Siwi $=3$ ATyas_Kartika $=3 \mathrm{~A}=$ 3A.html . Diunduh 7 Juni 2017

[5] Ryan, AS, Zhou, W \& Arensberg, MB. 2006. "The effect of employment status on breastfeeding in the United States." Women Health Issues. 16. 243-251 
[6] Nurpelita.2007. Faktor-faktor yang Berhubungan dengan Pemberian ASI Eksklusif di Wilayah Kerja Puskesmas Buatan II Siak Tahun 2007. Tesis. Fakultas Kesehatan Masyarakat Universitas Indonesia

[7] Fikawati, S., Syafiq, A., dan Karima, K. 2015. Gizi Ibu dan Bayi. Jakarta: Rajawali Pers

[8] Afifah DN. Faktor yang Berperan dalam Kegagalan Praktik Pemberian ASI Eksklusif (Studi Kualitatif di Kecamatan Tembalang, Kota Semarang Tahun 2007. Diakses dari: eprint.undip.ac.id/1034/1/ARTIKE L_ASI.pdf. Pada tanggal 8 September 2018.

[9] Roesli, Utami. 2001. Bayi Sehat Berkat ASI Eksklusif, Makanan Pendamping Tepat dan Imunisasi Lengkap. Jakarta: Alex Media Komputindi

[10] Angraresti, Irfa E dan Syauqy, Ahmad. 2016. Faktor-faktor Yang Berhubungan Dengan Kegagalan Pemberian ASI Eksklusif Di Kabupaten Semarang. Diakses dari: http://eprints.undip.ac.id/52211/1 /861_IRFA_EKA_ANGRARESTI.pdf. Pada tanggal 8 September 2018.

[11] Kurniawati, Dwi dan Hargono, Rachmat. 2014. Faktor Determinan Yang Mempengaruhi Kegagalan Pemberian ASI Eksklusif Pada Bayi Usia 0-6 bulan di Keluarhan Mulyorejo Wilayah Kerja Puskesmas Mulyorejo Surabaya. Diakses dari: http://journal.unair.ac.id/download full/JuPromkes8587bece $5 \mathrm{e} 0 \mathrm{ff} 9$ fullabstract.pdf.Pada tanggal 8 September 2018.
[12] Proverawati. 2010. Buku ajar kesehatan reproduksi untuk kebidanan.Yogyakarta:Nuha Medika

[13] Nurlinawati. 2016. Dukungan Keluarga Terhadap Pemberian Asi Eksklusif Pada Bayi Di Kota Jambi. Diakses dari:https://media.neliti.com/medi a/publications/70687-IDdukungan-keluarga-terhadappemberian-asi.pdf. Pada tanggal 8 September 2018.

[14] Roesli, Utami. 2008. Mengenal ASI Ekslusif. Jakarta : PustakaBunda.

[15] Roesli, Utami. 2009. Mengenal ASI Eksklusif. Jakarta: Trubus Agriwidya, Anggota IKAPI

[16] Notoatmodjo. 2010. Metode Penelitian Kesehatan. Jakarta: Rineka Cipta.

[17] Wijayanti, Hartanti Sandi, dkk. 2017. Faktor Risiko Kegagalan Asi Eksklusif. Journal of Nutrition College, Volume 6, Nomor 3, Tahun 2017. Diakses dari:http://ejournals1.undip.ac.id/index.php/jnc. Pada tanggal 9 September 2018.

[18] Notoatmodjo, S. 2007. Promosi Kesehatan dan Ilmu Perilaku. Jakarta: Penerbit Rineka Cipta

[19] Sulistiwaty, Ari. 2009. Asuhan Kebidanan pada ibu nifas.Yogyakarta: Andi

[20] Alamsyah, Dedi.2017. Hubungan antara kondisi kesehatan ibu, pelaksanaan imd, dan iklan susu formula dengan pemberian asi eksklusif.IKESMA, [S.I.], v. 13, n. 1. ISSN 1829-7773. Diakses dari: $<$ https://jurnal.unej.ac.id/index.ph p/IKESMA/article/view/7027>. doi: https://doi.org/10.19184/ikes ma.v13i1.7027. 